\title{
WOMEN'S PARTICIPATION IN SCIENCE, TECHNOLOGY ENGINEERING AND MATHEMATICS (STEM) EDUCATION: A REVIEW OF LITERATURE
}

\author{
Sadia Sajid \\ Department of Journalism, Faculty of Arts and Social Science \\ University Tunku Abdul Rahman (UTAR), Kampar \\ Malaysia \\ Sadiasajid@1utar.my

\section{Sultana Alam} \\ Department of Journalism, Faculty of Arts and Social Science \\ University Tunku Abdul Rahman (UTAR), Kampar \\ Malaysia \\ sultana@utar.edu.my

\section{Jin Kuan Kok} \\ Department of Journalism, Faculty of Arts and Social Science \\ University Tunku Abdul Rahman (UTAR), Kampar \\ Malaysia \\ kokjk@utar.edu.my

\section{Mobashar Rehman} \\ Department of Information Systems, Faculty of Information and Communication Technology \\ University Tunku Abdul Rahman (UTAR), Kampar \\ Malaysia \\ mobashar@utar.edu.my
}

*Corrosponding author's Email: sultana@utar.edu.my

Peer-review under responsibility of 4th Asia International Multidisciplinary Conference 2020 Scientific Committee http://connectingasia.org/scientific-committee/ (C) 2020 Published by Readers Insight Publisher, Office \# 6, First Floor, A \& K Plaza, Near D Watson, F-10 Markaz, Islamabad. Pakistan, 


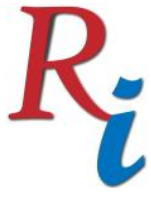

\section{Asia Proceedings of Social Sciences \\ (APSS) \\ www.readersinsight.net/APSS}

\section{A b s t r a c t}

The participation of females in Science, Technology, Engineering and Mathematics (STEM) fields has diminished globally. Although their participation in higher education is increasing, they are still significantly underrepresented in STEM fields. It is important to understand the forces at play, which drive women's choice of STEM education. A variety of factors impact the choice of females to take STEM path including personal (i.e. self-concept, self-efficacy, personal preferences, self-stereotyping and intrinsic motivation) as well as the external factors (i.e. role models, family, teacher's influence as well as low recruitment of women in STEM fields). This paper systematically reviews the literature on young women's intention to undertake STEM education in Malaysian context. The paper has adopted the PRISMA protocol for Systematic Literature Review (SLR). The paper has identified 10 research papers which have attempted to identify the factors effecting female participation in STEM education in Malaysian context. Furthermore, the paper has also highlighted the factors which have been identified by these studies as well as those personal and external factors which have not been studied extensively in Malaysian context. This paper can give readers a novel insight about factors influencing women's participation in STEM education in Malaysian context.

\section{Research High I ight s}

- This research paper systematically reviews the existing literature on young women's intention to undertake STEM education in Malaysian context.

- By using the PRISMA protocol for systematic literature review, the research has identified 10 studies which have attempted to identify the factors effecting female participation in STEM education in Malaysian context.

- Several factors have been discussed in the identified studies. However, several other important factors have been overlooked in Malaysian context.

- The study emphasizes the importance of conducting more research in the domain of gender disparity in STEM education in Malaysia 


\section{Asia Proceedings of Social Sciences (APSS) \\ www.readersinsight.net/APSS}

\section{Graphical A bstract}

\begin{tabular}{|c|c|c|}
\hline Methodology & $\begin{array}{l}\text { Factors Studied in } \\
\text { Existing Studies }\end{array}$ & Less Studied Factors \\
\hline $\begin{array}{l}\text { PRISMA } \\
\text { methodology for } \\
\text { systematic } \\
\text { literature review. } \\
\text { Identified } 10 \\
\text { studies in } \\
\text { Malaysian context }\end{array}$ & $\begin{array}{l}27 \text { factors identified } \\
\text { such as Governmental } \\
\text { Policies, Interest, } \\
\text { Family Influence, Role } \\
\text { Models, Self-efficacy, } \\
\text { High Salary, Health, } \\
\text { Safety, Learning } \\
\text { experience, } \\
\text { Educational choice, } \\
\text { Opportunity equality, } \\
\text { duration in school, } \\
\text { Work-family conflict, } \\
\text { Technostress, } \\
\text { Mentorship }\end{array}$ & $\begin{array}{l}\text { Self-concept, self- } \\
\text { efficacy, personal } \\
\text { factors, stereotyping, } \\
\text { intrinsic motivation, } \\
\text { role model influence, } \\
\text { family and teacher's } \\
\text { influence, low } \\
\text { recruitment levels }\end{array}$ \\
\hline
\end{tabular}

\section{Research Objectives}

The present research work aims to provide an overall picture of the literature on factors effecting female participation in STEM education in Malaysia. Following are the objectives of this research:

- To determine the factors which have been studied in prior literature as for their influence on female participation in STEM education in Malaysian context

- To identify factors which have not been discussed extensively in Malaysian context.

\section{Methodology}

In order to conduct the systematic review, a protocol was adopted from the Preferred Reporting Items for Systematic reviews and Meta-Analysis (PRISMA) (Moher et al, \& the PRISMA Group, 2010). The protocol includes determining the search string, execution of search, screening, eligibility and inclusion.

\section{Results}

Majority of the research work on factors influencing female participation in STEM education in Malaysia began after the year 2012. The result of the study highlighted 10 studies in Malaysian context which have studied the factors effecting female participation in STEM education in Malaysia. These factors include Governmental Policies, Interest, Family Influence, Role Models, Self-efficacy, High Salary, Health, Safety, Learning experience, 


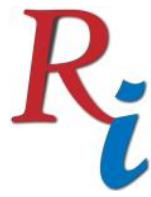

\section{Asia Proceedings of Social Sciences}

(APSS)

www.readersinsight.net/APSS

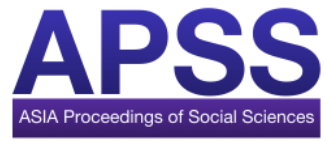

Educational choice, Opportunity equality, duration in school, Work-family conflict, Technostress, Mentorship, Self-Determination, Grade Motivation, Career Motivation, Governmental Investment, Family structure and women's commitment to family, Low Recruitment at the Point of Entry, Access \& Skills, Relevance, Empowerment, Combating Stereotypes.

On the other hand, the study has also shed light on the factors which are important but are relatively less studied. These include self-concept, self-efficacy, personal factors, stereotyping, intrinsic motivation, role model influence, family and teacher's influence, low recruitment.

\section{Findings}

The findings of the present research illustrated the current situation of the literature on female participation in STEM education in Malaysian context by using systematic literature review approach. It is evident from the results that the research work on this topic in Malaysian context is not sufficient and more needs to be done in this regard. Furthermore, important factors need to be studied extensively in Malaysian context, in order to generate reliable and generalizable results.

\section{Acknowledgement}

We would like to express our sincere gratitude to Universiti Tunku Abdul Rahman (UTAR) for providing the required funds to carry out this research work under Universiti Tunku Abdul Rahman Research Fund (UTARRF).

\section{References}

Moher, D., Liberati, A., Tetzlaff, J., Altman, D. G., \& The PRISMA Group. (2010). Preferred reporting items for systematic reviews and meta-analyses: The PRISMA statement. International Journal of Surgery, 8(5), 336-341. https://doi.org/10.1016/j.ijsu.2010.02.007

Author's Biography

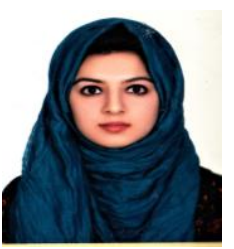

Sadia Sajid is a Master's student at the Department of Journalism, Faculty of Arts and Social Science, University Tunku Abdul Rahman (UTAR), Kampar. Prior to this, she has completed her Bachelor's in Business Administration (BBA) with specialization in Information Technology Management (ITM) from Islamic International University, Islamabad, Pakistan. Her research areas include STEM education and gender disparity. 


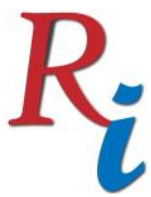

\section{Asia Proceedings of Social Sciences (APSS) \\ www.readersinsight.net/APSS}
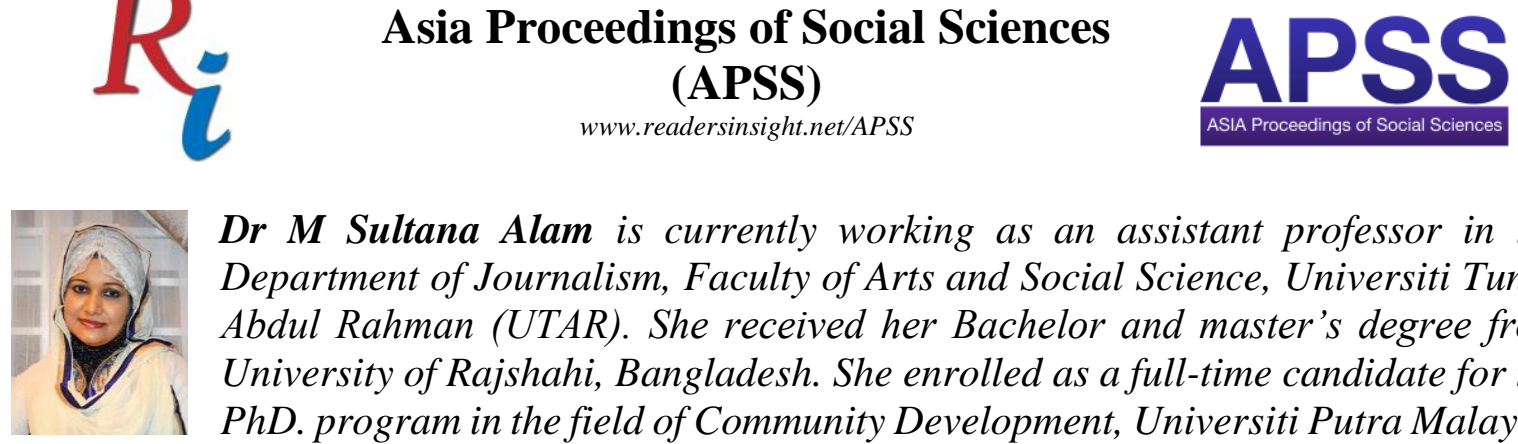

Dr M Sultana Alam is currently working as an assistant professor in the Department of Journalism, Faculty of Arts and Social Science, Universiti Tunku Abdul Rahman (UTAR). She received her Bachelor and master's degree from University of Rajshahi, Bangladesh. She enrolled as a full-time candidate for the PhD. program in the field of Community Development, Universiti Putra Malaysia (UPM), in November 2003. She completed her PhD. April 2006. She has published the number of articles in the refereed journals. Presently, she is focusing her research on women, STEM education, gender disparity, marriage and family.

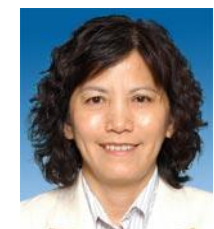

Dr. Jin Kuan Kok obtained her master's in Education (Guidance and Counselling) as well as her PhD in Education from Durham University, England, UK. She is currently an Associate Professor at the Department of Psychology and Counselling, Faculty of Arts and Social Science, Universiti Tunku Abdul Rahman (UTAR). Her areas of research include narrative inquiry, teenage suicide, depression narrative, holistic school counselling approach, higher education in Malaysia among others.

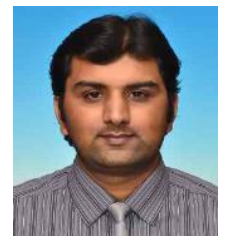

Dr. Mobashar Rehman received his Ph.D. in Information Technology from Universiti Teknologi Petronas (Knowledge Management). He is currently working as Assistant Professor at the Department of Information Systems, Universiti Tunku Abdul Rahman, Kampar, Malaysia. His research interests include knowledge management, knowledge sharing, human factors in Software Engineering, Machine Learning, Cyber-Psychology and STEM Education. 